\title{
Mechanical Properties as a Function of Zinc Content, Degree of Cold Drawing and Annealing Temperature in $\alpha$-Brasses.
}

\author{
R.A. Essawy, and A.M. Mostafa, \\ Solid State Physics Department, National Research Centre, \\ Dokki St., Cairo, Egypt
}

\begin{abstract}
Increasing zinc content up to $28 \mathrm{wt}$. \% zinc was found to increase stress level and ductility. Degrees of cold drawing up to $99 \%$ reduction in cross sectional area increase stress level while decrease ductility for the different $\mathrm{Cu}$ $\mathrm{Zn}$ alloys studied. Annealing after cold drawing increases ductility but decreases stress level. Abrupt decrease in ductility was observed after high temperature annealing of highly drawn wires and specially for alloys, with high $\mathrm{Zn}$ content. The results were discussed according to current solid solution hardening mechanisms, roughening of slip planes, locking of extended dislocations and difficulty of cross slipping.
\end{abstract}




\section{Introduction:}

Alloying is one of the most important methods to improve strength of metals. When brasses have the structure of $\alpha$-Solid solution, an increase in the zinc content causes an increase in both strength and ductility [1].

In $\alpha$ - brasses the zinc atoms replace copper atoms to form a random non homogeneous substitutional solid solution. The replacement process is quite indiscriminate so that the concentration of zinc atoms can vary considerably throughout the structure. This enhances diffusion to take place to produce more stable and uniform distribution [1-3].

When a polycrystalline metal is plastically deformed the individual grains tend to rotate into a common orientation (preferred orientation). For most face centred cubic metals and alloys, the texture is a combination of both $\langle 111>$ and $<100>$ texture. The degree of each depends on the degree of deformation, annealing temperature and the added solid solution alloying elements which generally lower stacking fault energy. It was accepted that $<111>$ texture is about $20 \%$ stronger than a random structure while $<100>$ is $20 \%$ weaker [4].

The purpose of this work is to discuss changes in mechanical properties as a function of zinc content up to 28 wt. \% zinc, cold drawing up to $99 \%$ decrease in cross sectional area and annealing at temperatures $400{ }^{\circ} \mathrm{C}$ and $700{ }^{\circ} \mathrm{C}$ for four hours, after cold drawing.

\section{Experimental Work:}

The commercial pure copper and copper-zinc alloys with 6,10 and 28 wt. \% zinc were used. The alloys were supplied by Helwan Company for NonFerrous metals in Egypt, in the form of rods $9 \mathrm{~mm}$. in diameter and of the chemical analysis shown in Table (1). Four rods $30 \mathrm{~cm}$. long from each of $\mathrm{Cu}$ and its three alloys were annealed at $400{ }^{\circ} \mathrm{C}$ for 6 hours under vacuum $\quad\left(10^{-}\right.$ ${ }^{6}$ torr.) for homogenization. The rods were then cold drawn without intermediate annealing to wires of decreasing diameters $(2.5,2,1.5$ and $1 \mathrm{~mm}$. corresponding to $92,95,97$ and 99 percent decrease in the initial cross sectional area, respectively. Some of each of the differently cold drawn wires were annealed under vacuum at $400{ }^{\circ} \mathrm{C}$ and others at $700{ }^{\circ} \mathrm{C}$ for four hours. Ultimate Tensile Stress U.T.S. and ductility percent ( $\xi \%)$ were measured according to the A.S.T.M. wire specifications using Instron 1128 Machine. 
Table (1)

\begin{tabular}{|l|c|c|c|c|}
\hline \multirow{2}{*}{ Materials } & \multicolumn{4}{|c|}{ Impurities \% } \\
\cline { 2 - 5 } & $\mathrm{Cu}$ & $\mathrm{Zn}$ & $\mathrm{Mg}$ & $\mathrm{Fe}$ \\
\hline $\mathrm{Cu}$ & 99.966 & 0.00 & 0.0300 & 0.0040 \\
$\mathrm{Cu}-6 \% \mathrm{Zn}$ & 93.810 & 6.11 & 0.0010 & 0.0790 \\
$\mathrm{Cu}-10 \% \mathrm{Zn}$ & 89.996 & 10.00 & 0.0024 & 0.0016 \\
$\mathrm{Cu}-28 \% \mathrm{Zn}$ & 71.989 & 28.00 & 0.0070 & 0.0040 \\
\hline
\end{tabular}

Texture, dislocation density $(\rho)$ and stacking fault probability $(\alpha)$ for the studied wires were quantitatively determined, under the same conditions elsewhere [5].

\section{Results and Discussion:}

Figures 1 to 3 show the obtained results for the studied wires Each of the three variable parameters studied (Zinc content, degree of cold drawing, and the annealing temperature after cold drawing) was followed at constancy of the other parameters.

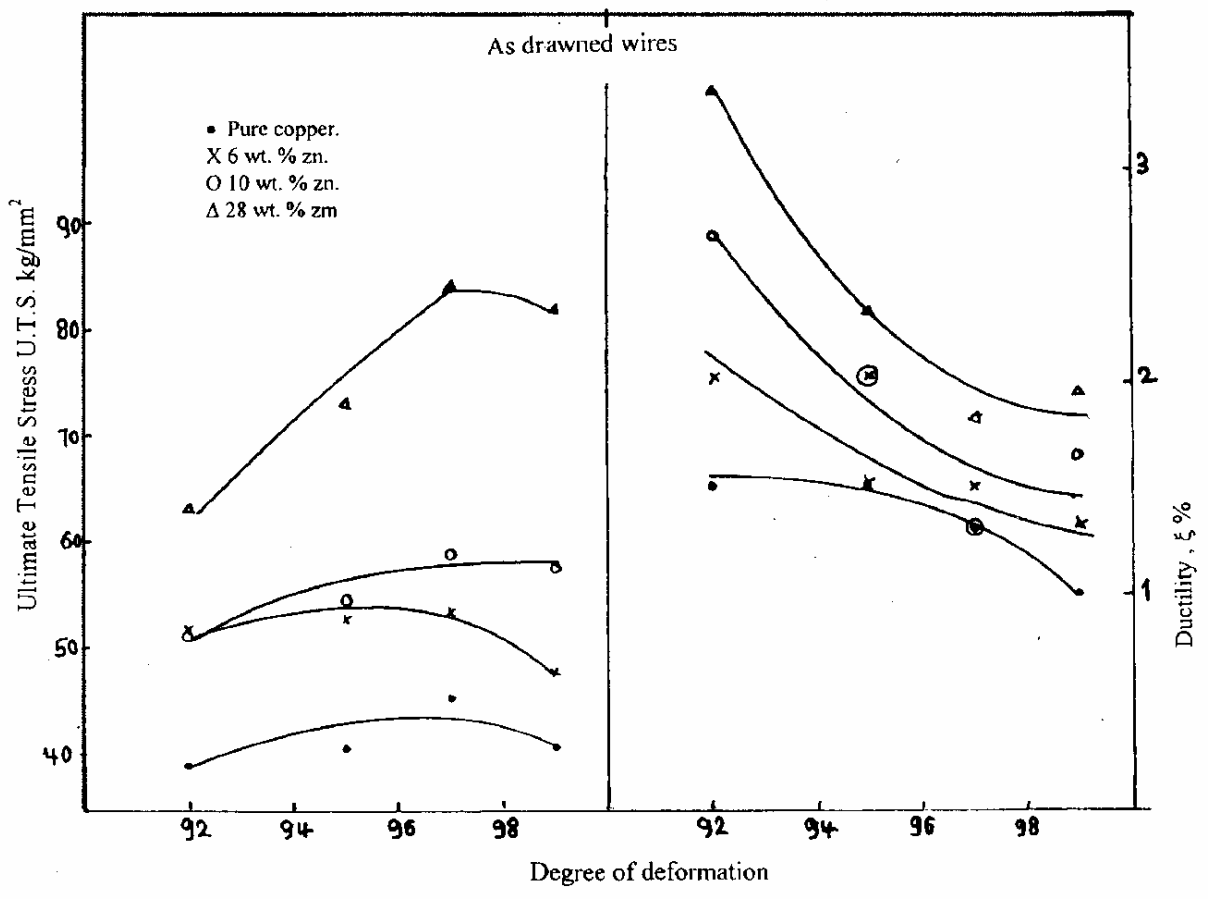

Fig.(1): Ultimate tensile stress and ductility as functions of degree of deformation for as drawn wires of brasses with different $\mathrm{Zn}$ content. 


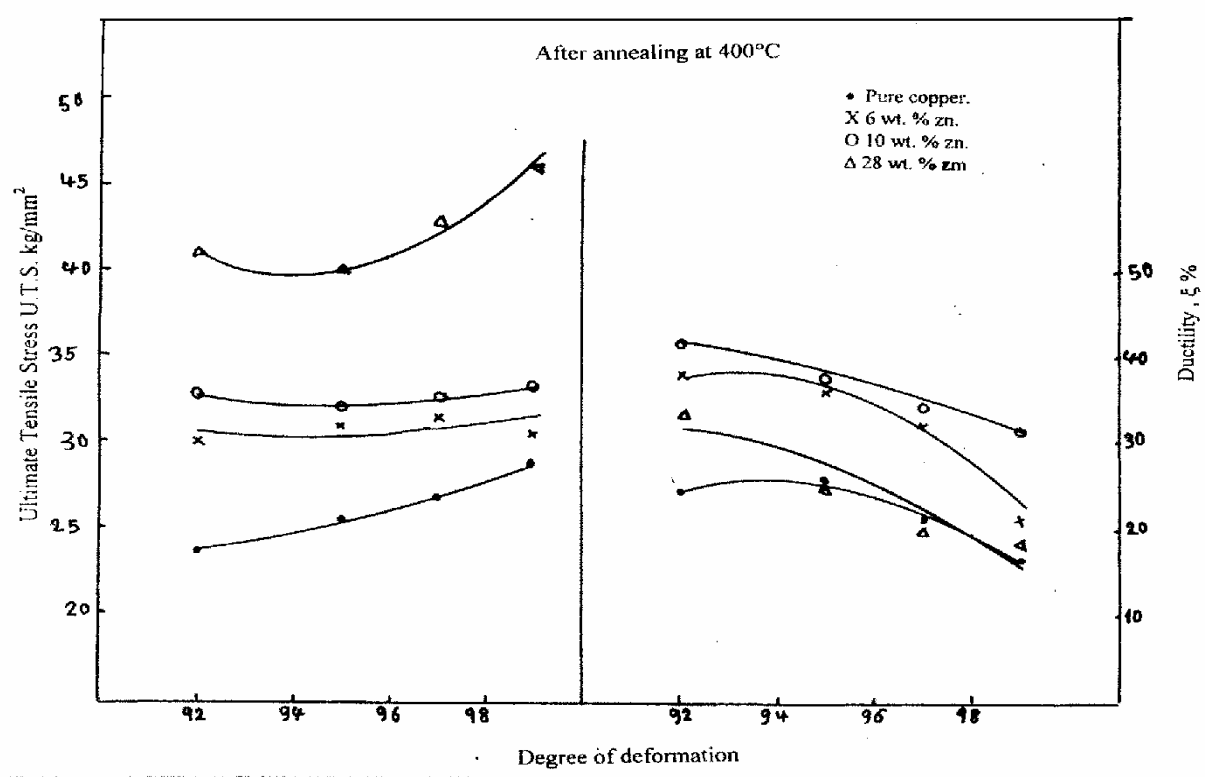

Fig.(2): Ultimate tensile stress and ductility as functions of degree of deformation for as drawn wires of brasses with different $\mathrm{Zn}$ content, (After annealing at $400^{\circ} \mathrm{C}$ ).

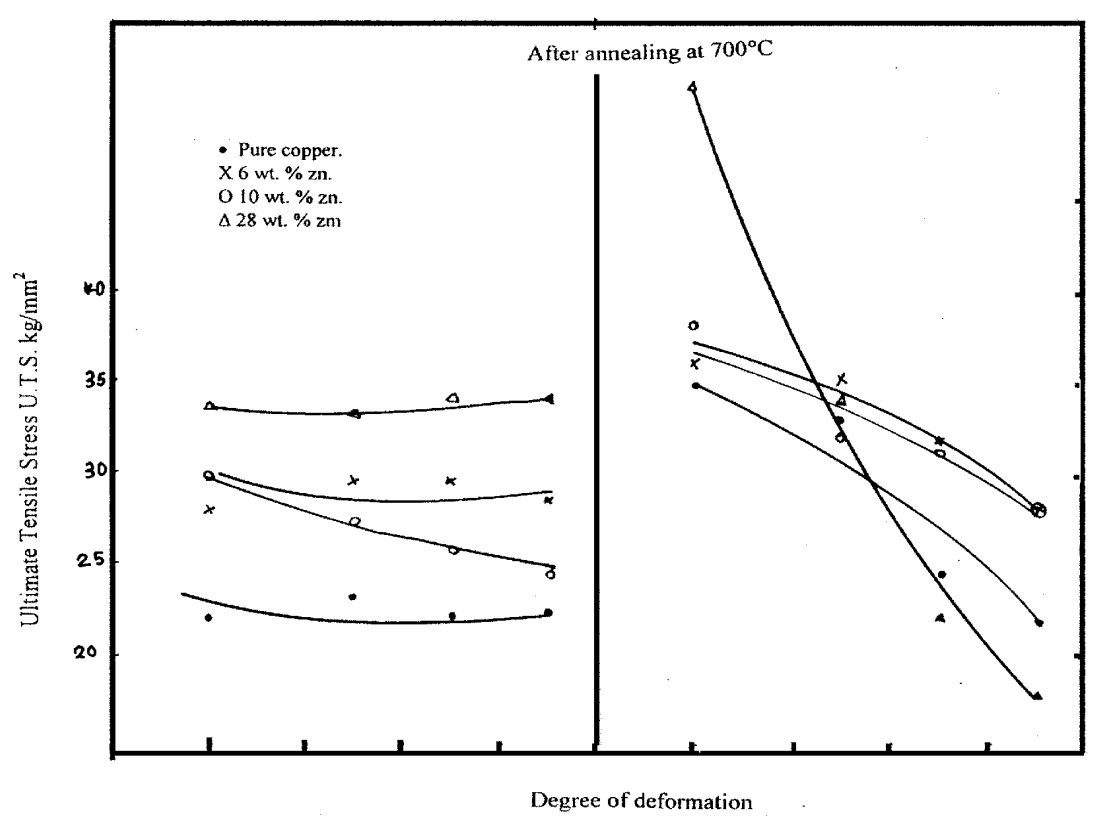

竞

Fig.(3): Ultimate tensile stress and ductility as functions of degree of deformation for as drawn wires of brasses with different $\mathrm{Zn}$ content, (After annealing at $700^{\circ} \mathrm{C}$ ). 
Figure (4) shows the increase of stress level with increasing zinc content at three increasing $<111>$ texture percentages in the wires [5].

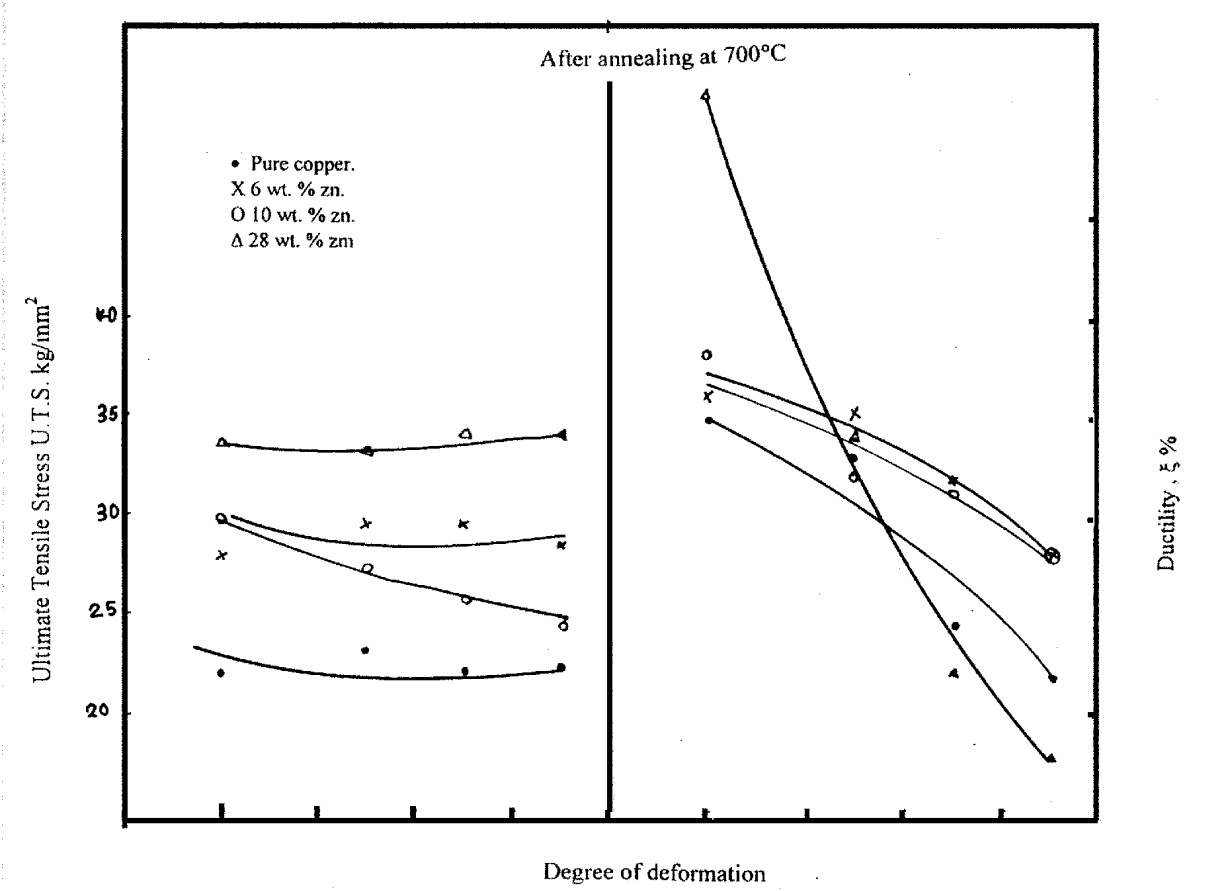

Fig.(4): The relation between U.T.S and $\mathrm{Zn}$ content for three different $<$ III $>$ texture degrees $\%$

$$
\begin{array}{ll}
\mathrm{X} & <\mathrm{III}>=95 \% \\
\Delta & <\mathrm{III}>=83 \% \\
\mathrm{O} & <\mathrm{III}>=72 \%
\end{array}
$$

The hardening in solid solution alloys is expected to be due to change in the mechanism of work hardening with alloying i.e changes in dislocation density, arrangement, interactions with each other and with contaminated other imperfections [6a].

Alloying with elements which lower the stacking fault energy changes work hardening behaviour in a similar way as does a decrease in temperature [3]. Dislocation dissociation (the process which is energetically favorable in F.C.C. structure metals and alloys results in the formation of stacking faults, cross slip becomes difficult specially in case of wide stacking faults in low stacking fault energy metals and alloys [7].The observed increase in stress level by increasing both the degree of cold drawing and the percent of zinc content can be discussed considering that in cold worked metals and alloys the increased number of dislocations by cold working [5], and in the presence of 
solute atoms cause distortion of the lattice [3]. Lattice can reduce its internal energy either through the dissociation of some of its dislocations forming stacking faults or by the segregation of the present solute atoms on dislocations. The movement of such dislocation configurations actually needs more energy to be applied $[6 \mathrm{~b}, 8,9]$.

Obtained results show that ductility increased by increasing zinc content. This can be discussed considering the case in low stacking fault energy alloys and due to the difficulty of cross slip. Chance of dislocation interactions decrease and so work hardening decreases in turn $[10,11]$. In stead of tangled and three dimensional net work structure of dislocations expected in pure $\mathrm{Cu}, \mathrm{a}$ planer arrangement of dislocations predominates in these alloys. In non homogeneous alloys like $\alpha$-Brasses preferential solute bonds are cut by the pass of the already present dislocations and successive ones find an easier passage on the same slip plane, so increasing slip distances $[10,11]$.

Changes in ductility and stress level by annealing at $400{ }^{\circ} \mathrm{C}$ and $700{ }^{\circ} \mathrm{C}$ after cold drawing seemed to be not highly affected by the formed textures. This result is supported by the increased percent of the $<111>$ texture on annealing at $700{ }^{\circ} \mathrm{C}$ than on annealing at $400{ }^{\circ} \mathrm{C}[4,5]$.

For samples having the same $\mathrm{Zn}$ content and deformed to the same degree, the decreased stress level and increased ductility by annealing was accepted to be due to the enhanced recovery and recrystallisation processes by annealing [12]. Redistribution of possibly formed short-range ordered or clustered zinc atoms in the matrix by annealing may be responsible for the decreased stress level, specially for concentrated alloys [13].

The observed decrease in ductility on annealing after high cold drawing and specially for the high concentrated alloy ( $28 \mathrm{wt}$. \% Zinc) may be due to the occurrence of grain growth and the decreased grain boundary area [12]

\section{References:}

1. R.A. Higgins, "Engineering Metallurgy" The English universities press Ltd, st. Paul's House Warwick Lane, London $\mathrm{Ec}_{4} \mathrm{P}_{4} \mathrm{AH}$ printed in great Britain (1975).

2. P. Haasen, in "Physical Metallurgy" Cambridge university press, Cambridge pp. 175-181 (1978).

3. R.W. Cahn, and P. Haasen, in "Physical Metallurgy" North Holland Physics Publishing Amsterdam Oxford New York Tokyo p. 1343 (1983).

4. Smallman, R.E. in "Modern physical metallurgy" Butter Worth and Co. publishers Ltd. p. 303 (1970). 
5. Moustafa, A.M., Partial fulfillment of the requirements for the Degree of Master of Science in Physics, Faculty of Science Cairo University, Cairo, Egypt (1995).

6. Haasen, P., "Strength of Materials and Alloys", Eds. Pergamon Press, Oxford, vol. 3, (1979).

a) Kubin, L.P. and Martin, J.L. P.1639.

b) Suzuki, H., P.1595.

7. Seeger A. in Handbuch d. phys. VII, 1, p. 1 Berlin Gottingen Heidelberg springer (1955).

8. B.G. Childs, and Le Claire, A.D., Acta Met., 2, 718 (1954).

9. R.L., Fleischer, Acta Met., 14, 1867, (1966).

10. C.B. Carter, and Ray, J.L., Phil. Mag., 35, 189, (1977).

11. R. E. Smallman, and R. J., Bishop, in "Metals and Materials" Butter Worth and Heinemann Ltd. (1995).

12. Soliman, M.R., Youssef, T.H. and Essawy, R.A., Indian Journal of Physics., 45, 77, (1971).

13. Dieter, G.E., in "Mechanical Metallurgy" Copyright by McGraw-Hill, Kogakusha Ltd., pp. 210 - 215, (1976). 